\title{
The Direct and Ecological Costs of an Ant-Plant Symbiosis
}

\section{Citation}

Frederickson, Megan E., Alison Ravenscraft, Gabirel A. Miller, Lina M. Arcila Hernández, Gregory Booth, and Naomi E. Pierce. 2012. The direct and ecological costs of an ant-plant symbiosis. The American Naturalist 179(6): 768-778.

\section{Published Version}

doi:10.1086/665654

\section{Permanent link}

http://nrs.harvard.edu/urn-3:HUL.InstRepos:9637883

\section{Terms of Use}

This article was downloaded from Harvard University's DASH repository, and is made available under the terms and conditions applicable to Other Posted Material, as set forth at http:// nrs.harvard.edu/urn-3:HUL.InstRepos:dash.current.terms-of-use\#LAA

\section{Share Your Story}

The Harvard community has made this article openly available.

Please share how this access benefits you. Submit a story.

\section{Accessibility}




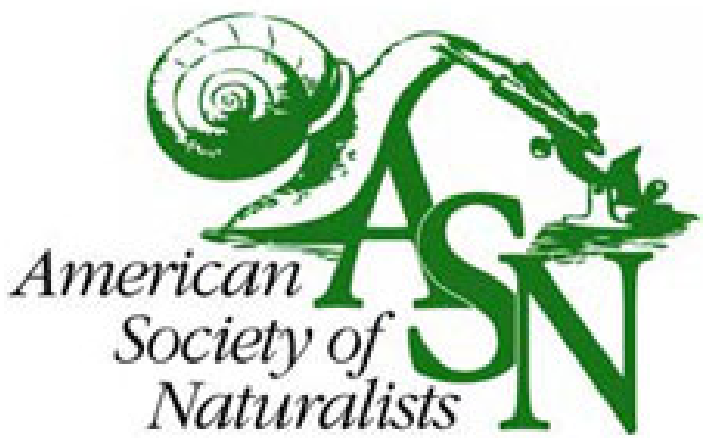

The Direct and Ecological Costs of an Ant-Plant Symbiosis.

Author(s): Megan E. Frederickson, Alison Ravenscraft, Gabriel A. Miller, Lina M. Arcila

Hernández, Gregory Booth, and Naomi E. Pierce

Reviewed work(s):

Source: The American Naturalist, Vol. 179, No. 6 (June 2012), pp. 768-778

Published by: The University of Chicago Press for The American Society of Naturalists

Stable URL: http://www.jstor.org/stable/10.1086/665654

Accessed: 12/06/2012 11:49

Your use of the JSTOR archive indicates your acceptance of the Terms \& Conditions of Use, available at http://www.jstor.org/page/info/about/policies/terms.jsp

JSTOR is a not-for-profit service that helps scholars, researchers, and students discover, use, and build upon a wide range of content in a trusted digital archive. We use information technology and tools to increase productivity and facilitate new forms of scholarship. For more information about JSTOR, please contact support@ jstor.org. 


\title{
The Direct and Ecological Costs of an Ant-Plant Symbiosis
}

\author{
Megan E. Frederickson, ${ }^{1, \star}$ Alison Ravenscraft, ${ }^{2}$ Gabriel A. Miller, ${ }^{3}$ Lina M. Arcila Hernández, \\ Gregory Booth, ${ }^{1}$ and Naomi E. Pierce ${ }^{3}$
}

1. Department of Ecology and Evolutionary Biology, University of Toronto, 25 Harbord Street, Toronto, Ontario M5S 3G5, Canada; 2. Department of Biology, Stanford University, Stanford, California 94305; 3. Department of Organismic and Evolutionary Biology, Harvard University, Cambridge, Massachusetts 02138

Submitted July 12, 2011; Accepted February 3, 2012; Electronically published April 25, 2012

Online enhancement: appendix. Dryad data: http://dx.doi.org/10.5061/dryad.144v45c6.

\begin{abstract}
Aвstract: How strong is selection for cheating in mutualisms? The answer depends on the type and magnitude of the costs of the mutualism. Here we investigated the direct and ecological costs of plant defense by ants in the association between Cordia nodosa, a myrmecophytic plant, and Allomerus octoarticulatus, a phytoecious ant. Cordia nodosa trees produce food and housing to reward ants that protect them against herbivores. For nearly 1 year, we manipulated the presence of A. octoarticulatus ants and most insect herbivores on C. nodosa in a full-factorial experiment. Ants increased plant growth when herbivores were present but decreased plant growth when herbivores were absent, indicating that hosting ants can be costly to plants. However, we did not detect a cost to ant colonies of defending host plants against herbivores. Although this asymmetry in costs suggests that the plants may be under stronger selection than the ants to cheat by withholding investment in their partner, the costs to $C$. nodosa are probably at least partly ecological, arising because ants tend scale insects on their host plants. We argue that ecological costs should favor resistance or traits other than cheating and thus that neither partner may face much temptation to cheat.
\end{abstract}

Keywords: Ant-plant interactions, cheating, costs of resistance, evolution of mutualism, indirect plant defense.

\section{Introduction}

Mechanisms that maintain cooperation and prevent cheating have been heavily emphasized in the mutualism literature (e.g., Pierce 1987; Sachs et al. 2004; Foster and Kokko 2006; Douglas 2008; Weyl et al. 2010). Although individuals may reap net benefits through cooperation, they may do even better by cheating and taking the benefits of cooperation without paying the costs of reciprocation. However, for natural selection to favor cheating over cooperation, it is necessary (although not sufficient) for cooperation to be costly. There is simply nothing to be gained from cheating in cost-free interactions, which are often

\footnotetext{
* Corresponding author; e-mail: m.frederickson@utoronto.ca.
}

Am. Nat. 2012. Vol. 179, pp. 768-778. (C) 2012 by The University of Chicago. 0003-0147/2012/17906-53179\$15.00. All rights reserved. DOI: $10.1086 / 665654$ termed "by-product mutualisms" (Connor 1995; Sachs et al. 2004; Douglas 2008). Therefore, understanding the costs of cooperation is central to predicting when cheating might evolve.

Ant-plant interactions are classic examples of mutualism (e.g., Janzen 1966) and have figured prominently in the literature on the evolution of mutualism (Bronstein 1998; Yu 2001; Heil and McKey 2003; Sachs et al. 2004; Frederickson 2009; Heil et al. 2009; Weyl et al. 2010). Numerous plant species make food or housing to attract ants, which defend the plants against herbivores or other enemies (reviewed by Heil and McKey 2003). These ants collect extrafloral nectar or food bodies from plants, and symbiotic species nest inside live plant cavities called domatia. These ant-plant relationships range from facultative interactions, in which plants typically associate with a diversity of free-living partners, to obligate interactions, which tend to be more species specific (Chamberlain and Holland 2009; Trager et al. 2010). In obligate associations, the plants and ants rely upon each other during much of their life cycles and are rarely found without each other. Here we refer to plant species that make domatia as myrmecophytic and ant species that nest in domatia as phytoecious.

Research on the costs of plant resistance to herbivores provides a useful framework for considering the costs of ant-plant interactions (e.g., Heil 2002; Strauss et al. 2002). The costs of ants to plants are direct costs if they arise from a trade-off between allocating resources to ants versus allocating resources to other functions like growth or reproduction. However, ants can also impose ecological costs on plants if they negatively affect the interactions between their host plants and other organisms in the environment. For example, ants can deter pollinators (Ness 2006) or increase herbivore loads on their host plants (Frederickson and Gordon 2007; Palmer et al. 2008), such as by tending scale insects or aphids (Styrsky and Eubanks 2007). Direct and ecological costs are tightly linked (e.g., investing in 
ants instead of growth may reduce a plant's competitive ability; see also Heil 2002), but nonetheless we think the distinction is useful because of the different implications of direct and ecological costs for the evolution of cheating. When mutualisms involve direct costs, cheaters can achieve higher fitness by investing more in growth or reproduction at the expense of the mutualism. However, it is less clear how individuals might minimize ecological costs by cheating (a term that we use throughout this article to mean withholding the benefits of mutualism). Instead, ecological costs may result in selection for resistance or other traits that do not amount to cheating. Returning to the above example, to keep ants off of flowers, where they can deter pollinators, some ant-acacias have evolved to defend their flowers with ant repellents (Willmer and Stone 1997; Ghazoul 2001; Raine et al. 2002; Nicklen and Wagner 2006) while still provisioning ants with domatia, food bodies, and/or extrafloral nectar.

Mutualisms can also involve other costs, but again they are unlikely to impose selection for cheating. Interacting with a mutualist can result in physical damage, such as the destruction of host reproductive structures by phytoecious ants (Yu and Pierce 1998; Stanton et al. 1999; Izzo and Vasconcelos 2002; Frederickson 2009). This cost of mutualism is also thought to result in selection for defense (e.g., tolerance; Edwards and Yu 2008) more often than in selection for cheating (but see Izzo and Vasconcelos 2002). The evolution of specialization can be considered to be another cost of mutualism (e.g., Bronstein 2001) because the participants lose evolutionary flexibility, such as the ability to live independently or associate with a more beneficial partner. However, costs resulting from specialization cannot be overcome by cheating and should instead result in selection for facultative associations or reversions to autonomy (Sachs and Simms 2006). Furthermore, specialization may also constrain the ability of mutualists to cheat (Moran and Wernegreen 2000). Hence, of the many varied costs of mutualism, only direct costs can unambiguously result in selection for cheating.

What do we already know about the direct costs inherent in ant-plant mutualisms? On the plant side, several studies have compared investment in ant rewards with investment in other functions. O'Dowd (1980) estimated that Ochroma pyramidale saplings invest about $1 \%$ as much in extrafloral nectar and food bodies as they do in leaves, and Heil et al. (1997) found that Macaranga triloba allocates about $5 \%$ of its aboveground biomass to food bodies. Four experimental studies have investigated the costs to plants of maintaining their associated ants. Three found equivocal evidence of costs: Rutter and Rausher (2004) found no negative genetic correlation between fitness and extrafloral nectar production in ant-excluded Chamaecrista fasciculata, and Rudgers (2004) and Rudgers and Strauss (2004) found no fitness differences between ant-excluded Gossypium thurberi producing normal and experimentally reduced amounts of extrafloral nectar. These results are surprising, given the apparent investment by the plant in providing food for ants, although the absence of evidence for costs in these studies does not necessarily amount to evidence of the absence of costs. In addition, C. fasciculata and G. thurberi form facultative associations with ants, and we might expect greater costs in obligate ant-plant symbioses. Indeed, the fourth study concluded that hosting ants is costly to the obligate antplant Acacia drepanolobium, on the basis of the results of a multiyear experiment in which exterminating ant colonies actually increased growth and/or reproduction of their host trees (Stanton and Palmer 2011).

On the ant side, few if any attempts have been made to measure the costs to ants of defending plants, even though this behavior is often assumed to be costly (e.g., Yu 2001; Edwards et al. 2006). Phytoecious ants that attack herbivores may or may not also eat them. If they do eat most of the herbivores they attack, then plant defense is likely to be directly beneficial to ants and herbivory reduction should be considered a cost-free or by-product benefit of ants foraging for insect prey on plant surfaces. Alternatively, if a phytoecious ant colony depends entirely on extrafloral nectar or food bodies for food (e.g., Heil et al. 2004) and workers mostly just chase away herbivores, then any resources the colony invests in patrolling or defending a plant may represent a direct cost to the ant colony. For example, workers might expend energy or suffer increased mortality while protecting their host plant.

Here we investigated the direct and ecological costs of defense by the phytoecious ant Allomerus octoarticulatus (Formicidae: Myrmicinae) to the myrmecophytic plant Cordia nodosa (Boraginaceae). We manipulated the presence of ants and most insect herbivores on C. nodosa saplings for almost 1 year in a full-factorial experiment. We predicted that if maintaining A. octoarticulatus colonies is costly to C. nodosa, then in the absence of herbivores, having ants should reduce plant performance. Similarly, if defending C. nodosa against herbivores is costly to $A$. octoarticulatus, then colonies should perform better in the absence than in the presence of herbivores.

\section{Material and Methods \\ Study Site and System}

This study was conducted at the Los Amigos Research Center $\left(12^{\circ} 34^{\prime} \mathrm{S}, 70^{\circ} 05^{\prime} \mathrm{W}\right.$; elevation, $\left.\sim 270 \mathrm{~m}\right)$, in the Department of Madre de Dios, Peru. Surrounding the research center is the Los Amigos conservation concession, which comprises 146,000 ha of primary tropical rain forest 
on a mixture of upland terraces and floodplains. Annual rainfall at Los Amigos is between 2,700 and 3,000 mm, with more than $80 \%$ of the precipitation falling during the October-April wet season (Pitman 2008). Mean monthly temperatures range from $21^{\circ}$ to $26^{\circ} \mathrm{C}$ (Pitman 2008).

At Los Amigos and elsewhere in the western Amazon Basin, Cordia nodosa associates with several species of ants. The most common is Allomerus octoarticulatus (Myrmicinae), which occupies $40 \%-80 \%$ of $C$. nodosa trees in this region (Yu and Pierce 1998; Frederickson 2009). Other $C$. nodosa are occupied by Azteca spp. (Dolichoderinae, 10\%$35 \%$ of trees), Myrmelachista schumanni (Formicinae, $<2 \%$ of trees), or other twig-nesting ant species (very rarely), or else they are not occupied by ants at all $(10 \%-20 \%$ of primarily very young trees; Yu and Pierce 1998; Frederickson 2009). Cordia nodosa produces domatia-hollow stem swellings on otherwise slender branches (fig. 1) regardless of whether ants are present. Each time a $C$. nodosa tree grows a new shoot, it produces one domatium together with a whorl of new leaves. If the tree has ants, the colony quickly fills this new domatium with brood and workers. Cordia nodosa trees produce food bodies on the surfaces of young leaves and shoots as a reward for ants (Solano et al. 2005). Allomerus octoarticulatus colonies also obtain additional food from the honeydew-producing scale insects (Hemiptera: Sternorrhyncha: Coccoidea) they tend inside the domatia (fig. 1). In southeastern Peru, A. octoarticulatus appears to be an obligate symbiont of C. nodosa (Yu and Pierce 1998), but this species specificity breaks down at larger geographic scales. In Brazil, ants identified as A. octoarticulatus have been collected from Duroia saccifera, Hirtella myrmecophila, Hirtella physophora, Remejia physophora, and Tococa spp. (Wheeler 1942; Fonseca 1999; Izzo and Vasconcelos 2002; Fernández 2007). Although further work is needed to determine whether these collections represent a single species or a complex of closely related species (Fernández 2007), genetic data indicate that throughout the Peruvian Amazon the Allomerus ants found in C. nodosa are all from one species (Debout et al. 2009).

Previous research on this system has shown that $A$. octoarticulatus defends $C$. nodosa against folivores: the presence of A. octoarticulatus ants significantly reduces folivory in ant-exclusion experiments (Yu and Pierce 1998; Fred-

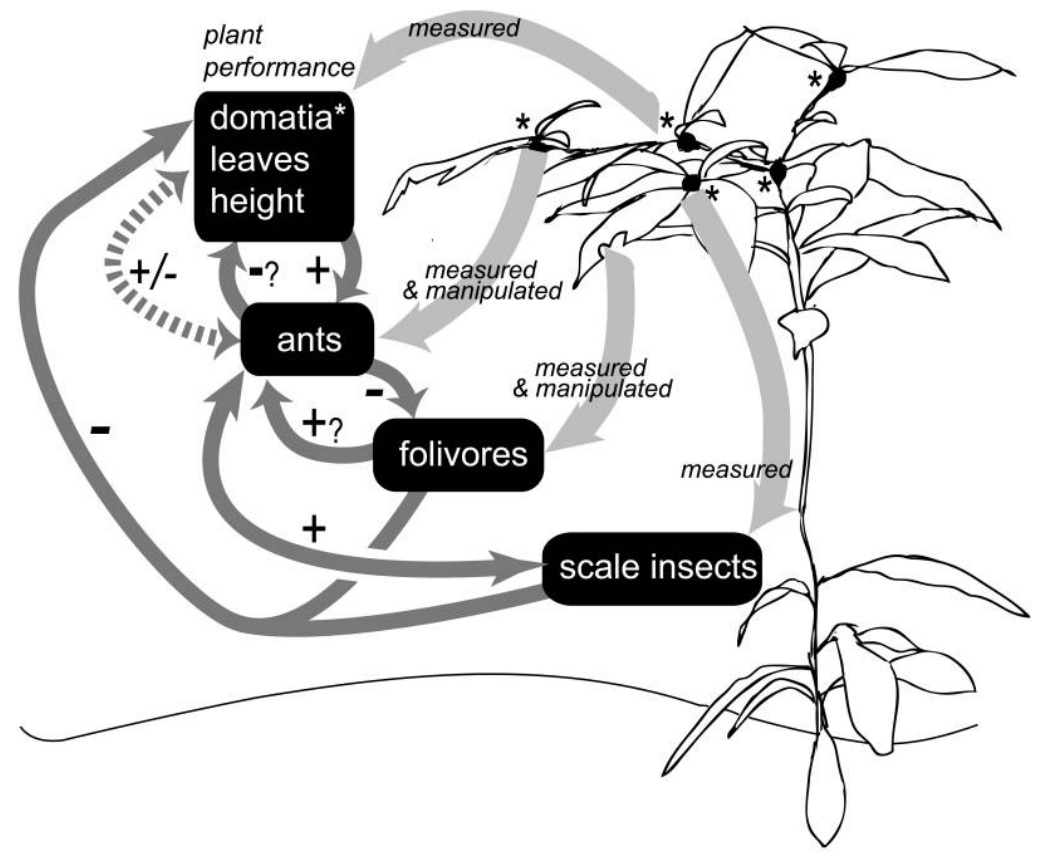

Figure 1: Interaction web showing the principal cost and benefit pathways between Allomerus octoarticulatus ant colonies and Cordia nodosa plants, as well as the participants manipulated and the variables measured in this experiment. Cordia nodosa houses ants and scale insects in domatia (black swellings next to asterisks). Ants reduce folivory but facilitate scale insects. Direct costs to plants of hosting ants come from the production of ant rewards (i.e., domatia, food bodies), whereas ecological costs include the loss of resources to ant-tended scale insects. Solid lines are direct interactions and dashed lines are indirect interactions; some direct and many indirect pathways are omitted for clarity. Lifetime fitness measurements for plants and ants (e.g., seed or alate production) were not possible over the timescale of our experiment, but plant performance is a good surrogate. See text for details. 
erickson 2005). Some important folivores of C. nodosa are adult and larval leaf beetles (i.e., Chrysomelidae) and orthopterans. It has also been shown that $A$. octoarticulatus sterilizes $C$. nodosa inflorescences, reducing $C$. nodosa fruit production by up to $100 \%$, which benefits the ants because sterilized plants produce more domatia and thus house larger, more fecund ant colonies (Yu and Pierce 1998; Dejean et al. 2004; Frederickson 2005, 2009; Szilágyi et al. 2009). In this study, C. nodosa plants were harvested before they reached reproductive maturity, so the sterilization behavior of A. octoarticulatus was not included as a factor in our experimental design.

\section{Experimental Addition or Exclusion of Ants and Herbivores}

In 2008, we collected more than 100 fruits from 20 mature C. nodosa trees at Los Amigos, removed the pulp, and abraded the seeds and sowed them in seedling trays. When a seed had germinated and produced two fully expanded cotyledons, we transplanted the seedling to its own grow bag. We put plants in grow bags inside two large Lumite screen outdoor cages (BioQuip Products) to keep them free of ants and herbivores, and then we left the plants to grow under ambient light and rainfall conditions for $>1$ year.

In July 2009, 52 C. nodosa saplings with at least one domatium were ready for transfer from their outdoor cages. For each of these saplings, we measured the height of the sapling, counted the number of leaves and domatia, and then marked each domatium individually with a thin, plastic-coated wire. We divided the plants into 13 blocks of four plants on the basis of their sizes, and within each block we assigned each plant at random to one of four treatments. The treatments were as follows: (1) ants excluded, herbivores present $(\mathrm{A}-\mathrm{H}+)$; (2) ants added, herbivores present $(\mathrm{A}+\mathrm{H}+)$; (3) ants excluded, herbivores excluded $(\mathrm{A}-\mathrm{H}-)$; and (4) ants added, herbivores excluded $(\mathrm{A}+\mathrm{H}-)$. We planted the saplings in the rain forest understory such that each sapling in a block formed the corner of a $2 \mathrm{~m} \times 2 \mathrm{~m}$ square; blocks were separated by 3-30 m along a trail. We hung a mosquito net over each C. nodosa sapling as we planted the trees. We then built 1 -m-tall wire fences around each group of four plants to keep mid- to large-sized mammals from making holes in the mesh nets.

We added queenright $A$. octoarticulatus colonies to $C$. nodosa saplings in the $\mathrm{A}+$ treatment. We collected the colonies from small, naturally occurring C. nodosa trees and counted the workers. We then transferred each colony to a small plastic bag and hung the bags on the recipient plants; over the next 1-5 days, the ant colonies moved from the bags into the domatia of the recipient plants. All but two colonies survived the transfer to new host plants; the two colonies that died were replaced with new ant colonies, using the same protocol.

Larger plants received larger ant colonies, but otherwise, ant colonies were assigned to recipient plants at random. Because of a scarcity of small C. nodosa trees at the study site and to allow for some worker mortality during the transfer, we collected ant colonies from plants that were somewhat larger than the experimental plants onto which the colonies were moved. Recipient plants with one domatium received ant colonies from plants with one to four domatia; recipient plants with two domatia received ant colonies from plants with four to seven domatia; recipient plants with three domatia received ant colonies from plants with seven or eight domatia; and recipient plants with four to eight domatia received ant colonies from plants with nine domatia. As a result, there was a significant relationship between plant size (i.e., number of domatia, squareroot transformed) and ant colony size (i.e., number of workers, square-root transformed) at the beginning of the experiment ( $\left.n=26, R^{2}=0.21, P=.017\right)$. A similar correlation is observed in naturally occurring $A$. octoarticulatus colonies nesting in C. nodosa trees (L. M. Arcila Hernández, unpublished data).

To prevent ants from colonizing plants assigned to the A - treatment, we injected with a syringe $0.2 \mathrm{~mL}$ of a dilute, nonsystemic, pyrethroid insecticide (Cypermethrin, $0.2 \mathrm{mg} / \mathrm{mL}$ ) into each domatium at the beginning of the experiment (August 2009) and again in November 2009 and February 2010. All A- plants received insecticide. When applying the insecticide, we took care to avoid contact between the insecticide and any plant parts other than the inside of domatia. Leaf-chewing insects fed on the leaves associated with insecticide-treated domatia; damage by folivores to $\mathrm{A}-\mathrm{H}+$ plants was high (see "Results"). We did not monitor visits or damage by sap-sucking insects or other herbivores, and so we do not know whether the insecticide reduced other forms on herbivory on the Aplants. However, in a pilot study, no significant differences were observed in plant growth over 3 months between ant-free C. nodosa plants treated with Cypermethrin and ant-free controls ( $n=12$; results not shown).

To maintain similar light environments among treatments, all plants were planted inside mesh nets. The nets covering plants in the $\mathrm{H}-$ treatment were staked securely to the ground. The nets covering plants in the $\mathrm{H}+$ treatment were rolled up so their bottoms hung $\sim 30 \mathrm{~cm}$ off the ground, which is a height that allowed access by most insect herbivores but kept leaves similarly shaded underneath the nets as in the $\mathrm{H}-$ treatment. We used a Li-Cor LI-250A light meter equipped with a LI-190SA quantum sensor (Forestry Suppliers) to measure photosynthetically active radiation (PAR) inside and outside the nets at the beginning (August 2009), middle (February 2010), and 
end (June-July 2010) of the experiment. The light environment did not differ among treatments, nor did it differ significantly between the outside and the inside of the nets; see the appendix, available online, for the complete PAR results and analysis. Between August 2009 and May 2010, the plants were monitored monthly. We checked the integrity of the mesh nets and repaired holes as necessary. In February 2010, all 52 mesh nets were replaced with new, larger mosquito nets.

Plants spent a total of 314-329 days in the experiment. In late June and early July 2010, we harvested the plants, collecting one block of four plants each day. We first measured the height of each plant and then cut off, counted, and labeled all of the leaves, aspirating any ants on the leaves into a plastic vial. We also cut off domatia and placed them into individually labeled envelopes that, along with the plant stems, were sealed into Ziploc bags to prevent ants from escaping. Allomerus octoarticulatus workers do not venture off their host plants, even when disturbed, so we are confident that we collected almost all of the ants in each colony. To kill the ants and other insects, bags of domatia and stems as well as vials of aspirated ants were frozen for 24-72 h. We cut open each domatium and counted all of the worker ants and scale insects (i.e., mealy bugs and soft scales) inside, and then we preserved the entire ant colony (workers, brood, and queen) in 95\% ethanol. We also preserved a subset of the scale insects that we found in the domatia; taxonomic identification revealed that the scale insects included the mealy bugs Dysmicoccus texensis, Dysmicoccus brevipes, Nipaecoccus cf. nipae, and Leptococcus neotropicus and the soft scales Coccus hesperidum and Pulvinaria floccifera. Because we did not collect all of the scale insects from each plant, other species may also have been present.

In the field, one of us (G.B.) visually estimated percent folivory for each leaf $(n=4,196)$, using a score of $0-20$. We also digitally photographed each leaf against a white background. For a random subsample of 25 leaves per treatment, we measured percent folivory in the digital images, using ImageJ. We analyzed the relationship between the visually estimated scores and the ImageJ results (fig. A1, available online; $R^{2}=0.83 ; P<.001$ ) and used the least squares regression equation to convert the visual scores to percent folivory values. We calculated percent folivory for each plant as the mean value for all of its leaves.

\section{Statistical Analysis}

Four of the 13 blocks of plants did not finish the experiment with all of the treatments intact, so these blocks were excluded from the data analysis. In three blocks, one or both of the ant colonies died before the end of the experiment (two colonies in the $\mathrm{H}+$ treatment and two in the $\mathrm{H}$ - treatment). In the fourth block, one of the plants lost all of its leaves, apparently because of a fungal pathogen. To improve normality, we square-root transformed all count data (i.e., numbers of ants, scale insects, domatia, and leaves), as well as folivory data, then logtransformed the height data. When we measured several correlated variables, we used principal components (PC) analysis to reduce the data. We used mixed-model ANOVAs or ANCOVAs to analyze the effects of the experimental treatments on folivory, plant size, ant colony size, and number of scale insects, all measured at the end of the experiment. For the folivory data, the ANOVA model included ant treatment $(\mathrm{A}+$ or $\mathrm{A}-)$, herbivore treatment $(\mathrm{H}+$ or $\mathrm{H}-)$, and their interaction effect as fixed factors and block and block $\times$ treatment interaction effects as random factors. The ANCOVA model for final plant size had all of these same factors as well as initial plant size as a covariate. For ant colony size and number of scale insects, we modeled data only from plants with ants (i.e., A+ plants). The ANCOVA model for final colony size included the final number of domatia and initial colony size as covariates and herbivore treatment $(\mathrm{H}+$ or $\mathrm{H}-$ ) as the categorical variable. Similarly, the model for the number of scale insects included final colony size as a covariate and herbivore treatment as a fixed factor. All statistical analyses were performed in JMP 9.0.0. Data are deposited in the Dryad repository (Dryad Data: http:// dx.doi.org/10.5061/dryad.144v45c6).

\section{Results \\ Folivory}

Ants significantly reduced folivory on plants, but they were not as effective in reducing folivory as the herbivore-exclusion treatment (fig. 2; ant treatment effect: $F_{1,8}=14.93$, $P=.005$; herbivore treatment effect: $F_{1,8}=22.31, P=$ .002 ; ant $\times$ herbivore interaction effect: $F_{1,8}=14.04$, $P=.006)$. Folivory was very localized, as indicated by the significant block $\times$ herbivore treatment interaction effect $\left(F_{8,8}=10.02, \quad P=.002\right)$. However, the block effect $\left(F_{8,8}=0.851, P=.589\right)$ and the block $\times$ ant treatment interaction effect $\left(F_{8,8}=0.868, P=.577\right)$ were not significant.

\section{Plant Growth}

The effect of ants on plant growth depended on whether herbivores were present (fig. 3). We combined our three highly correlated measures of plant size-namely, height, number of domatia, and number of leaves - using PC analysis (see the appendix for the complete univariate re- 


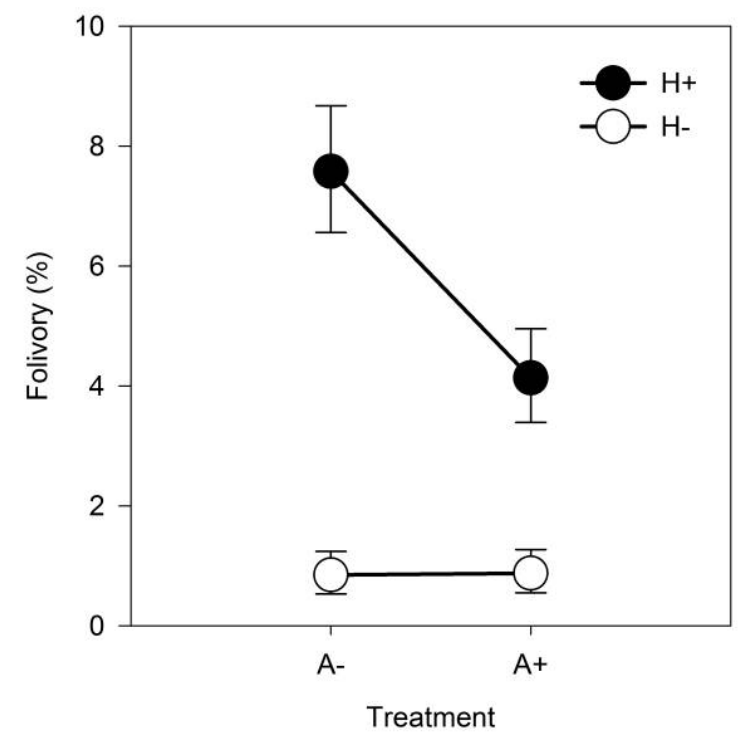

Figure 2: Standing percent folivory on Cordia nodosa plants at the end of the experiment. Shown are back-transformed least squares means; error bars indicate 95\% CIs. Most insect herbivores had access to plants symbolized by filled circles $(\mathrm{H}+)$ but were excluded from plants symbolized by open circles $(\mathrm{H}-)$. Plants with and without ants are indicated by $\mathrm{A}+$ and $\mathrm{A}-$, respectively.

sults). PC1 explained $73 \%$ and $93 \%$ of the variation in initial and final plant size, respectively, and was the only PC with an eigenvalue greater than 1 in both analyses. As a result, we used PC1 for initial and final plant size in the subsequent ANCOVA. The ANCOVA showed that ants increased plant growth when herbivores were present but decreased plant growth when herbivores were absent (initial plant size: $F_{1,7}=8.71, P=.021$; ant treatment effect: $F_{1,8}=1.41, P=.270$; herbivore treatment effect: $F_{1,8}=$ 3.14, $P=.115$; ant $\times$ herbivore interaction effect: $\left.F_{1,7}=13.85, P=.007\right)$. There was also a significant interaction between block and herbivore treatment $\left(F_{8,7}=\right.$ 20.77, $P<.001)$, but no significant effects were observed with block alone $\left(F_{8,9}=1.32, P=.342\right)$ or block $\times$ ant treatment $\left(F_{8,7}=2.56, P=.117\right)$.

The costs of ants to plant growth were large. As per Strauss et al. (2002), we calculated the magnitude of costs as $(1-$ [mean final plant size with ants/mean final plant size without ants] $) \times 100$ and found that associating with ants resulted in an $18 \%$ cost in height, a $40 \%$ cost in the number of domatia, and a $36 \%$ cost in the number of leaves.

\section{Ant Colony Growth}

At the end of the experiment, ant colonies were larger in the presence than in the absence of herbivores (least squares means [95\% CI]: for $\mathrm{H}+, 817$ [511-1,195] workers; for H-, 495 [265-797] workers), but the difference was not statistically significant (herbivore treatment effect: $\left.F_{1,14}=1.96, P=.184\right)$. There was a significant effect of final plant size (i.e., number of domatia: $F_{1,14}=4.65$, $P=.049)$ but not initial colony size $\left(F_{1,14}=0.01, P=\right.$ .944) in the ANCOVA model. We did not find winged males or females in the Allomerus octoarticulatus colonies we collected, which suggests that the colonies were not yet reproductively active.

\section{Scale Insects}

Compared with plants in the ant-addition treatments, plants in the ant-exclusion treatments had few scale insects (back-transformed means [95\% CI]: for A+, 60 [37-90] scale insects; for A-, 1.2 [0-4.5] scale insects). This difference is unlikely to be an artifact of applying insecticide to A- domatia. Similarly small numbers of scale insects were found in ant-free Cordia nodosa domatia that had not been treated with insecticide; the four $\mathrm{A}+$ plants with ant colonies that died during the experiment harbored totals of zero, one, two, and four scale insects at the end of the experiment. Thus, in the absence of ants, few scale insects recruit to or survive in C. nodosa domatia.

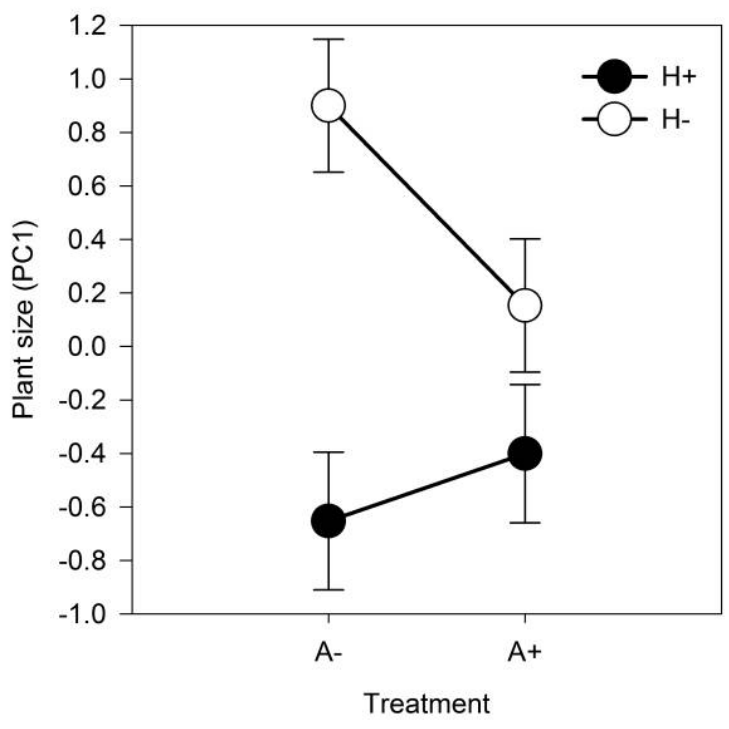

Figure 3: Size of Cordia nodosa plants at the end of the experiment, measured as the first principal component (PC1) of height, number of domatia, and number of leaves. Shown are least squares means; error bars indicate 95\% CIs. Most insect herbivores had access to plants symbolized by filled circles $(\mathrm{H}+)$ but were excluded from plants symbolized by open circles $(\mathrm{H}-)$. Plants with and without ants are indicated by $\mathrm{A}+$ and $\mathrm{A}-$, respectively. 


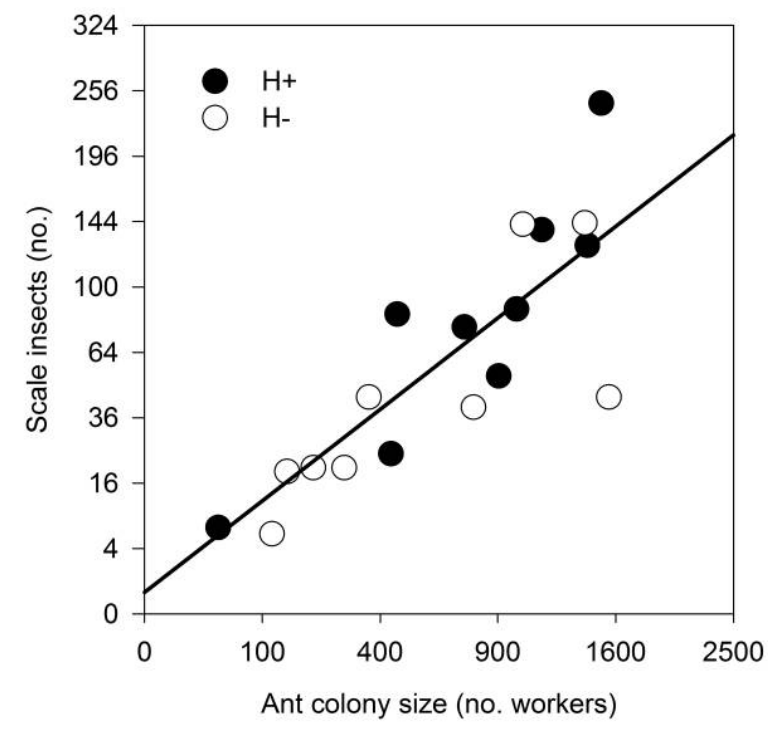

Figure 4: Relationship between the number of scale insects and the number of Allomerus octoarticulatus workers in a Cordia nodosa plant. The line represents the least squares regression. Most insect herbivores had access to plants symbolized by filled circles $(\mathrm{H}+)$ but were excluded from plants symbolized by open circles $(\mathrm{H}-)$.

In the ant-addition treatments, the total number of scale insects was strongly and positively correlated with ant colony size at the end of the experiment, and this relationship did not differ between herbivore treatments (fig. 4; herbivore treatment effect: $F_{1,15}=1.51, P=.239$; ant colony size effect: $\left.F_{1,15}=32.83, P<.001\right)$. Therefore, the mesh nets that excluded other herbivores from $C$. nodosa had little impact on scale insect populations, either because the crawlers were small enough to pass through the mesh or because some scale insects colonized plants when the $A$. octoarticulatus colonies were moved at the beginning of the experiment.

\section{Discussion}

\section{Costs of Ant Defense to Cordia nodosa}

We found that hosting an Allomerus octoarticulatus colony is costly to C. nodosa. In the absence of herbivores, plants with ants were $18 \%$ shorter and had $40 \%$ fewer domatia and $36 \%$ fewer leaves than plants without ants at the end of the experiment. The only other experimental study to find evidence for costs in an ant-plant system likewise found that hosting ants is apparently costly for the plant, although the design of that study did not allow the costs to be measured separately from the benefits of using ants for defense (Stanton and Palmer 2011). Numerous studies have found that ant rewards are produced sparingly, which certainly suggests that they are costly to make. For example, Heil et al. (2001) and Palmer et al. (2008) showed that both domatia and extrafloral nectar production can be induced by herbivory, and plants often produce extrafloral nectar and food bodies on only young, expanding leaves, which are the most vulnerable to folivory (Coley and Barone 1996). However, other previous tests of the costs of ants to plants have been inconclusive (i.e., Rudgers 2004; Rudgers and Strauss 2004; Rutter and Rausher 2004).

If larger $C$. nodosa plants have higher fitness, our results show that there is a selective disadvantage to hosting ants when they are not needed to attack or deter herbivores. Previous work on this system suggests that plant size is a key component of fitness for C. nodosa. In a multiyear study of C. nodosa demography, Frederickson and Gordon (2009) found that smaller plants are more likely to die than larger plants and C. nodosa trees live much longer than their ant colonies: an estimated 77 years for a $C$. nodosa tree, compared with only 7.8 years for an $A$. octoarticulatus colony. The same study showed that after an ant colony dies, a plant will get smaller until it also dies, unless a new queen founds a colony in its domatia and reverses the growth trend; larger plants are therefore more likely to survive periods between ant occupations and reach sexual maturity. An unresolved issue is what effect sterilization of $C$. nodosa floral buds by A. octoarticulatus has on plant fitness (Frederickson 2009). We know that sterilized plants grow faster (Frederickson 2009); larger plants, in turn, are more likely to survive until they are colonized by other, nonsterilizing ant species (Frederickson and Gordon 2009), and once they are occupied by nonsterilizing ants, larger $C$. nodosa trees produce more fruit (Yu and Pierce 1998). Therefore, although sterilization substantially reduces current reproduction (Frederickson 2009; Szilágyi et al. 2009), it may enhance future reproduction and ultimately have little or even a positive effect on lifetime fitness (as suggested for Acacia drepanolobium in Palmer et al. 2010). Cumulatively, the evidence indicates that the smaller size of plants with ants than without ants that we observed in the absence of herbivores likely has fitness implications for $C$. nodosa, but the benefits of housing ant colonies outweigh the costs when herbivores are present.

The costs to $C$. nodosa of hosting A. octoarticulatus could be direct costs if they result from the allocation of resources to feeding or housing ants. However, even though making domatia may be costly, this is unlikely to explain the results of our experiment because $C$. nodosa produces domatia regardless of whether ants are present (fig. A2 $b$, available online), and the presence of ants does not increase domatia size (M. E. Frederickson, A. Ravenscraft, L. M. Arcila Hernández, and G. A Miller, unpublished data). Unlike some 
other ant-plants (e.g., A. drepanolobium; Palmer et al. 2008), C. nodosa exhibits little phenotypic plasticity in the production of domatia; in effect, every new branch has a hollow swelling, and the number of domatia is the same as the number of internodes on a tree. Ants change the number of domatia on a tree by affecting plant growth but do not increase the density of domatia on branches. Our results show that in the absence of herbivores, plants with ants grow less and make fewer domatia than plants without ants (figs. 3, A2b). Therefore, the differences in plant performance that we observed among treatments most likely reflect the costs to $C$. nodosa of feeding A. octoarticulatus colonies.

Allomerus octoarticulatus colonies do not leave their host plants to forage for food (Yu and Pierce 1998). Instead, they consume food from several on-plant sources: (1) they eat the food bodies that $C$. nodosa produces on new shoots and leaves, (2) they consume the honeydew produced by the scale insects they tend inside domatia (and they may also prey on the scale insects themselves), and (3) they eat the arthropods that visit C. nodosa (Yu and Pierce 1998). For C. nodosa, the first of these is a direct cost, the second is an ecological cost, and the third is a benefit (fig. 1). Thus, in the absence of herbivores, the slower growth of C. nodosa trees with ants than without ants may result from the direct cost of provisioning ants with food bodies or from the ecological cost of losing resources to the scale insects that the ants tend inside domatia.

If the cost of having ants is related to food-body production, then plants with ants must invest more resources in food bodies than plants without ants. One possibility is that ants induce food-body production, which has been shown in other ant-plant species (Letourneau 1990; Folgarait and Davidson 1994; Heil et al. 1997). We saw food bodies on young leaves in all of the treatments in our experiment, but we did not measure whether the rate of food body production differed between ant-occupied and ant-free trees. Even if the rate of production did not differ, C. nodosa may reabsorb the contents of food bodies if they are not removed and consumed by ants. This mechanism would benefit the plant not only because they would recover scarce resources but also because in the absence of ants, nutrient-rich food bodies may attract herbivores or pathogens (Folgarait and Davidson 1994).

In addition to the cost of provisioning ants with food bodies, C. nodosa occupied by A. octoarticulatus also lose resources to scale insects. The strong correlation between the number of scale insects and the number of ants in a plant (fig. 4) suggests both that $A$. octoarticulatus relies heavily on scale insects for food and that the scale insects depend on their ant partners to survive and multiply on C. nodosa trees. The strong interdependence of $A$. octoarticulatus colonies and the scale insects they tend is sur- prising because the scale insects are mostly common, widely distributed, and highly generalist species. Scale insects and other hemipterans can impose substantial costs on plant fitness in both natural and agricultural ecosystems (Styrsky and Eubanks 2007), and some of the species we collected are well-known plant pests (e.g., Coccus hesper$i d u m)$. Therefore, we think the scale insects probably reduced plant performance in our experiment and may be responsible for a substantial portion of the costs of defense by A. octoarticulatus to C. nodosa (fig. 1). Unfortunately, our experimental design did not allow us to separate the costs to C. nodosa of making food bodies from the costs of hosting scale insects.

The high costs of maintaining ants (Stanton and Palmer 2011; this study) may help to explain why myrmecophytism is restricted to the tropics. If herbivores impose stronger selection on plant investment in defense in tropical areas than in temperate areas (Coley and Barone 1996; Rasmann and Agrawal 2011; but see Moles et al. 2011), the benefits of resistance may be larger in the tropics and may overcome even substantial costs. For example, in their recent meta-analysis, Chamberlain and Holland (2009) found that ants reduced herbivory more on ant-associated plants in tropical than in temperate ecosystems. Unfortunately, because almost all previous research on the costs of resistance has focused on temperate herbaceous plants (Bergelson and Purrington 1996; Strauss et al. 2002), it is presently not possible to evaluate whether the intensity of selection on resistance traits increases toward the equator and/or whether other factors come into play, such as changes in plant physiology, that might also affect the costbenefit ratios of myrmecophytism in different habitats (e.g., King and Caylor 2010). The former hypothesis is consistent with observations of greater investment by tropical plants in defense (Coley and Barone 1996; Rasmann and Agrawal 2011), including their greater investment in indirect defenses like ants.

\section{Costs of Plant Defense to A. octoarticulatus}

We could not detect a cost to A. octoarticulatus of defending C. nodosa against herbivores. Much like larger plants, larger ant colonies are likely to have higher fitness, because the production of reproductives by A. octoarticulatus colonies is highly correlated with C. nodosa size (Yu and Pierce 1998; Frederickson 2006; Frederickson and Gordon 2009), which is also correlated with ant colony size (i.e., number of workers; this study). Although ant colonies were almost twice as large on average in the $\mathrm{H}+$ treatment than in the $\mathrm{H}-$ treatment at the end of the experiment, this difference was not statistically significant because of the large variance in ant colony size and the small number of replicates in each 
treatment (nine); further study will be necessary to investigate this possible relationship.

Another explanation for our results is that the costs to A. octoarticulatus of patrolling and defending C. nodosa are fixed and did not vary significantly between treatments. During the experiment, we observed large numbers of workers on the young leaves of both the $\mathrm{H}+$ and the $\mathrm{H}-$ plants. A previous study of this system assumed that patrolling young leaves imposes a direct cost to A. octoarticulatus colonies, because the resources tied up in patrollers could otherwise have been used to make reproductives (Edwards et al. 2006). However, workers not only patrol plants, they simultaneously engage in actively gathering food for their colonies. Allomerus octoarticulatus workers that visit young leaves both collect food bodies and attack the insect herbivores that are attracted to these tender, nutritious leaves. Attacking insect herbivores may represent defense to $C$. nodosa, but it represents foraging for food to A. octoarticulatus and may directly benefit $A$. octoarticulatus colonies.

A similar argument has been made about pollinators going back at least as far as Darwin (1876, p. 419), who said,

That insects should visit the flowers of the same species for as long as they can, is of great importance to the plant, as it favours the cross-fertilization of distinct individuals of the same species; but no one will suppose that insects act in this manner for the good of the plant.

Unlike in plant-pollinator interactions, however, in symbiotic ant-plant associations an ant colony can derive both a direct benefit from foraging for insects as food and an indirect benefit from the increased growth of their host plant when the plant is released from herbivory. Some phytoecious ants may consume nothing but extrafloral nectar and/or food bodies (e.g., Pheidole bicornis [Fischer et al. 2002] and Pseudomyrmex on Acacia [Heil et al. 2004]), even though they have been shown to significantly reduce herbivory on their hosts (Janzen 1967; Letourneau et al. 1998), in which case they may reap only the indirect benefits of plant defense. But many, such as A. octoarticulatus, eat at least some of the insects that visit their host plants (e.g., Yu and Pierce 1998; Tillberg 2004). These ants are probably not under strong selection to cheat by not protecting their host plants against herbivores, and they might be expected to be more effective against palatable herbivores than unpalatable ones.

\section{Cheating and the Evolution of Mutualism}

How strong is the temptation to cheat in the ant-plant symbiosis between A. octoarticulatus and C. nodosa? Our results show that hosting $A$. octoarticulatus is costly to $C$. nodosa, so one might therefore expect that plant investment in ant rewards should be subject to stabilizing selection, with the optimal investment determined by the balance between the benefits of having ants to reduce herbivory and the costs of feeding or housing them. However, although C. nodosa could reduce its direct costs by skimping on the production of food bodies or other ant rewards, it is less clear how C. nodosa might cheat to reduce its ecological costs, such as the loss of resources to scale insects. We speculate that this cost may instead result in selection for resistance traits, such as tough inner walls in domatia or the production of secondary chemicals in plant sap. Similarly, another cost of hosting A. octoarticulatus that becomes apparent only when $C$. nodosa begins to flower is host-plant sterilization by this ant species (Yu and Pierce 1998; Frederickson 2009), and again C. nodosa may have evolved a defensive mechanism to minimize this cost: Edwards and Yu (2008, p. 95) proposed that C. nodosa "tolerates castration by directing floral growth to new shoots," where ants are less likely to attack flowers. Therefore, even in situations where mutualism is maintained at a cost, selection may not favor cheating if the cost is not a direct one.

Our results suggest that plant defense may be a byproduct benefit of A. octoarticulatus workers foraging for insect prey on their host plants. In general, we expect cheating by not defending a host plant to evolve more readily in systems where ants rely exclusively on their host plants for food than in those where resident ants eat herbivorous insects. Other ant behaviors, such as pruning vegetation or removing epiphytes from host plants, may be more prone to invasion by cheaters, although even these behaviors have been suggested to be directly beneficial to the ants in some ant-plant systems (Davidson et al. 1988).

Most plant-animal mutualisms, not just ant-plant systems, result from plants benefiting from animal foraging. For example, most animals that transfer pollen between flowers or disperse seeds do so as they forage for nectar, pollen, or fruit. In general, vectoring pollen or seeds is probably no more costly to these animals than protecting C. nodosa by foraging for insect prey is to A. octoarticulatus. Therefore, selection for cheating (by failing to move pollen or seeds while still consuming nectar, pollen, or fruit) within pollinating or seed-dispersing animal lineages should be relatively rare and confined to those interactions in which reciprocating the mutualism is costly. This may explain why many "cheaters" in plant-animal mutualisms are not derived evolutionarily from mutualistic lineages (i.e., they are "cheating from without," sensu Bronstein et al. 2006). Conversely, rewarding animals is often costly to plants (e.g., Pyke 1991), but whether these costs are largely direct or ecological is an open question. Thus, the asymmetry in costs that we observed between $C$. nodosa and 
A. octoarticulatus may be the norm in plant-animal mutualisms. Measurement of direct and ecological costs in other systems may provide further insight into the evolution of cheating and the persistence of mutualisms.

\section{Acknowledgments}

We thank G. Watson of the California Department of Food and Agriculture and D. Kondo of the Corporación Colombiana de Investigación Agropecuaria (CORPOICA) for identifying scale insects; I. Aggarwal for analyzing leaf im ages; A. Coral, L. Flores Quispe, and J. Sanders for field assistance; the staff at the Los Amigos Research Center for logistics; and the Peruvian Ministry of Agriculture for issuing permits (394-2009-AG-DGFFS-DGEFFS and 792008-INRENA-IFFS-DCB). We also thank members of the Thomson and Frederickson laboratories at the University of Toronto for comments and discussion and M. Heil, M. Stanton, and three anonymous reviewers for their insightful comments on earlier drafts. This research was fundec $\rightarrow$ by a Natural Sciences and Engineering Research Council Discovery Grant (to M.E.F.) and a National Science Foundation grant (SES-0750480; to N.E.P.). G.A.M. was supported by a Foundational Questions in Evolutionary Biology Postdoctoral Fellowship from Harvard University(funded by the Templeton Foundation), A.R. was supported by a Benjamin A. Trustman Fellowship from Harvard University, and G.B. was funded by the Independen $\rightarrow$ Experiential Study Program of the Faculty of Arts and Science at the University of Toronto.

\section{Literature Cited}

$\rightarrow$ Bergelson, J., and C. B. Purrington. 1996. Surveying patterns in the cost of resistance in plants. American Naturalist 148:536-558.

$\rightarrow$ Bronstein, J. L. 1998. The contribution of ant-plant protection studies $\rightarrow$ to our understanding of mutualism. Biotropica 30:150-161.

$\rightarrow \longrightarrow$. 2001. The costs of mutualism. American Zoologist 41:825839.

$\rightarrow$ Bronstein, J. L., R. Alarcón, and M. Geber. 2006. The evolution $\mathrm{o}_{\mathbf{r}} \rightarrow$ plant-insect mutualisms. New Phytologist 172:412-428.

$\rightarrow$ Chamberlain, S. A., and J. N. Holland. 2009. Quantitative synthesi, $\rightarrow$ of context dependency in ant-plant protection mutualisms. Ecology 90:2384-2392.

$\rightarrow$ Coley, P. D., and J. A. Barone. 1996. Herbivory and plant defenses in tropical forests. Annual Review of Ecology and Systematics 27. $\rightarrow$ 305-335.

$\rightarrow$ Connor, R. C. 1995. Altruism among non-relatives: alternatives to the "Prisoner's Dilemma." Trends in Ecology \& Evolution 10:84-86.

Darwin, C. R. 1876. The effects of cross and self fertilization in the vegetable kingdom. John Murray, London.

$\rightarrow$ Davidson, D. W., J. T. Longino, and R. R. Snelling. 1988. Pruning of host plant neighbors by ants: an experimental approach. Ecolog, 69:801-808.
Debout, G. D. G., M. E. Frederickson, M. E., S. Aron, and D. W. Yu. 2009. Unexplained split sex ratios in the Neotropical plantant, Allomerus octoarticulatus var. demerarae (Myrmicinae): a test of hypotheses. Evolution 64:126-141.

$\rightarrow$ Dejean, A., A. Quilichini, J. H. C. Delabie, J. Orivel, B. Corbara, and M. Gibernau. 2004. Influence of its associated ant species on the life history of the myrmecophyte Cordia nodosa in French Guiana. Journal of Tropical Ecology 20:701-704.

$\rightarrow$ Douglas, A. E. 2008. Conflicts, cheats and the persistence of symbioses. New Phytologist 177:849-858.

Edwards, D. P., and D. W. Yu. 2008. Tolerating castration by hiding flowers in plain sight. Behavioral Ecology and Sociobiology 63:95102.

Edwards, D. P., M. Hassall, W. J. Sutherland, and D. W. Yu. 2006. Selection for protection in an ant-plant mutualism: host sanctions, host modularity, and the principal-agent game. Proceedings of the Royal Society B: Biological Sciences 273:595-602.

Fernández, F. 2007. The myrmicine ant genus Allomerus Mayr (Hymenoptera: Formicidae). Caldasia 29:159-175.

Fischer, R. C., A. Richter, W. Wanek, and W. Mayer. 2002. Plants feed ants: food bodies of myrmecophytic Piper and their significance for the interaction with Pheidole bicornis ants. Oecologia (Berlin) 133:186-192.

Folgarait, P. J., H. L. Johnson, and D. W. Davidson. 1994. Responses of Cecropia to experimental removal of Müllerian bodies. Functional Ecology 8:22-28.

$\rightarrow$ Fonseca, C. R. 1999. Amazonian ant-plant interactions and the nesting space limitation hypothesis. Journal of Tropical Ecology 15: 807-825.

Foster, K. R., and H. Kokko. 2006. Cheating can stabilize cooperation in mutualisms. Proceedings of the Royal Society B: Biological Sciences 273:2233-2239.

Frederickson, M. E. 2005. Ant species confer different partner benefits on two Neotropical myrmecophytes. Oecologia (Berlin) 143:387395.

$\rightarrow-2006$. The reproductive phenology of an Amazonian ant species reflects the seasonal availability of its nest sites. Oecologia (Berlin) 149:418-427.

$\rightarrow-$ 2009. Conflict over reproduction in an ant-plant symbiosis: why Allomerus octoarticulatus ants sterilize Cordia nodosa trees. American Naturalist 173:675-681.

Frederickson, M. E., and D. M. Gordon. 2007. The devil to pay: a cost of mutualism with Myrmelachista schumanni ants in "devil's gardens" is increased herbivory on Duroia hirsuta trees. Proceedings of the Royal Society B: Biological Sciences 274:1117-1123.

. 2009. The intertwined population biology of two Amazonian myrmecophytes and their symbiotic ants. Ecology 90:1595-1607.

Ghazoul, J. 2001. Can floral repellents pre-empt potential ant-plant conflicts? Ecology Letters 4:295-299.

$\rightarrow$ Heil, M. 2002. Ecological costs of induced resistance. Current Opinion in Plant Biology 5:1-5.

Heil, M., and D. McKey. 2003. Protective ant-plant interactions as model systems in ecological and evolutionary research. Annual Review of Ecology, Evolution, and Systematics 34:425-453.

$\rightarrow$ Heil, M., B. Fiala, K. E. Linsenmair, G. Zotz, and P. Menke. 1997. Food body production in Macaranga triloba (Euphorbiaceae): a plant investment in anti-herbivore defence via symbiotic ant partners. Journal of Ecology 85:847-861.

Heil, M., T. Koch, A. Hilpert, B. Fiala, W. Boland, and K. E. Linsenmair. 2001. Extrafloral nectar production of the ant-associated 
plant Macaranga tanarius is an induced, indirect defensive response elicited by jasmonic acid. Proceedings of the National Academy of Sciences of the USA 98:1083-1088.

$\rightarrow$ Heil, M., B. Fiala, R. Krüger, and K. E. Linsenmair. 2004. Main nutrient compounds in food bodies of Mexican acacia ant-plants. Chemoecology 14:45-52.

$\rightarrow$ Heil, M., M. González-Teuber, L. W. Clement, S. Kautz, M. Verhaagh, and J. C. Silva Bueno. 2009. Divergent investment strategies of Acacia myrmecophytes and the coexistence of mutualists and ex ploiters. Proceedings of the National Academy of Sciences of the USA 106:18091-18096.

$\rightarrow$ Izzo, T. J., and H. L. Vasconcelos. 2002. Cheating the cheater: domati: $\rightarrow$ loss minimizes the effects of ant castration in an Amazonian antplant. Oecologia (Berlin) 133:200-205.

$\rightarrow$ Janzen, D. H. 1966. Coevolution of mutualism between ants anc $\rightarrow$ acacias in Central America. Evolution 20:249-275.

- 1967. Interaction of the bull's horn acacia Acacia cornigerw $\rightarrow$ L. with an ant inhabitant Pseudomyrmex ferruginea F. Smith in eastern Mexico. University of Kansas Science Bulletin 47:315-558.

$\rightarrow$ King, E. G., and K. K. Caylor. 2010. Herbivores and mutualistic ants interact to modify tree photosynthesis. New Phytologist 187:17-21.

$\rightarrow$ Letourneau, D. K. 1990. Code of ant-plant mutualism broken by parasite. Science 248:215-217.

$\rightarrow \longrightarrow$. 1998. Ants, stem-borers, and fungal pathogens: experimental tests of a fitness advantage in Piper ant-plants. Ecology 79:593-603.

$\rightarrow$ Moles, A. T., S. P. Bonser, A. G. B. Poore, I. R. Wallis, and W. J. Foley. 2011. Assessing the evidence for latitudinal gradients in plant defence and herbivory. Functional Ecology 25:380-388.

$\rightarrow$ Moran, N. A., and J. J. Wernegreen. 2000. Lifestyle evolution in symbiotic bacteria: insights from genomics. Trends in Ecology \& Evolution 15:321-326.

$\rightarrow$ Ness, J. H. 2006. A mutualism's indirect costs: the most aggressive plant bodyguards also deter pollinators. Oikos 113:506-514.

$\rightarrow$ Nicklen, E. F., and D. Wagner. 2006. Conflict resolution in an antplant interaction: Acacia constricta traits reduce ant costs to reproduction. Oecologia (Berlin) 148:81-87.

$\rightarrow$ O’Dowd, D. J. 1980. Pearl bodies of a Neotropical tree, Ochrome pyramidale: ecological implications. American Journal of Botany 67:543-549.

$\rightarrow$ Palmer, T. M., M. L. Stanton, T. P. Young, J. R. Goheen, R. M. Pringle and R. Karban. 2008. Breakdown of an ant-plant mutualism follows the loss of large herbivores from an African savanna. Science 319:192-195.

$\rightarrow$ Palmer, T. M., D. F. Doak, M. L. Stanton, J. L. Bronstein, E. T. Kiers T. P. Young, J. R. Goheen, and R. M. Pringle. 2010. Synergy of multiple partners, including freeloaders, increases host fitness in a multispecies mutualism. Proceedings of the National Academy of Sciences of the USA 107:17234-17239.

Pierce, N. E. 1987. The evolution and biogeography of associationbetween lycaenid butterflies and ants. Pages 89-116 in P. H. Harvey and L. Partridge, eds. Oxford surveys in evolutionary biology. Vol IV. Oxford University Press, Oxford.

Pitman, N. C. A. 2008. An overview of the Los Amigos watershed Madre de Dios, southeastern Peru. http://cicra.acca.org.pe/ espanol/paisaje_biodiversidad/los-amigos-overview9.pdf.

$\rightarrow$ Pyke, G. H. 1991. What does it cost a plant to produce floral nectar? Nature 350:58-59.

$\rightarrow$ Raine, N. E., P. Willmer, and G. N. Stone. 2002. Spatial structuring and floral avoidance behavior prevent ant-pollinator conflict in a Mexican ant-acacia. Ecology 83:3086-3096.

$\rightarrow$ Rasmann, S., and A. A. Agrawal. 2011. Latitudinal patterns in plant defense: evolution of cardenolides, their toxicity and induction following herbivory. Ecology Letters 14:476-483.

$\rightarrow$ Rudgers, J. A. 2004. Enemies of herbivores can shape plant traits: selection in a facultative ant-plant mutualism. Ecology 85:192205.

Rudgers, J. A., and S. Y. Strauss. 2004. A selection mosaic in the facultative mutualism between ants and wild cotton. Proceedings of the Royal Society B: Biological Sciences 271:2481-2488.

Rutter, M. T., and M. D. Rausher. 2004. Natural selection on extrafloral nectar production in Chamaecrista fasciculata: the costs and benefits of a mutualism trait. Evolution 58:2657-2668.

Sachs, J. L., and E. L. Simms. 2006. Pathways to mutualism breakdown. Trends in Ecology \& Evolution 21:585-592.

Sachs, J. L., U. G. Mueller, T. P. Wilcox, and J. J. Bull. 2004. The evolution of cooperation. Quarterly Review of Biology 79:135-160.

Solano, P. J., M. Belin-Depoux, and A. Dejean. 2005. Formation and structure of food bodies in Cordia nodosa (Boraginaceae). Comptes Rendus Biologies 328:642-647.

Stanton, M. L., and T. M. Palmer. 2011. The high cost of mutualism: effects of four species of East African ant symbionts on their myrmecophyte host tree. Ecology 92:1073-1082.

Stanton, M. L., T. M. Palmer, T. P. Young, A. Evans, and M. L. Turner. 1999. Sterilization and canopy modification of a swollen thorn acacia tree by a plant-ant. Nature 401:578-581.

$\rightarrow$ Strauss, S. Y., J. A. Rudgers, J. A. Lau, and R. E. Irwin. 2002. Direct and ecological costs of resistance to herbivory. Trends in Ecology \& Evolution 17:278-284.

$\rightarrow$ Styrsky, J. D., and M. D. Eubanks. 2007. Ecological consequences of interactions between ants and honeydew-producing insects. Proceedings of the Royal Society B: Biological Sciences 274:151-164.

$\rightarrow$ Szilágyi, A., I. Scheuring, D. P. Edwards, J. Orivel, and D. W. Yu. 2009. The evolution of intermediate castration virulence and ant coexistence in a spatially structured environment. Ecology Letters 12:1306-1316.

$\rightarrow$ Tillberg, C. 2004. Friend or foe? a behavioral and stable isotopic investigation of an ant-plant symbiosis. Oecologia (Berlin) 140: 506-515.

Trager, M. D., S. Bhotika, J. A. Hostetler, G. V. Andrade, M. A. Rodriguez-Cabal, C. S. McKeon, C. W. Osenberg, and B. M. Bolker. 2010. Benefits for plants in ant-plant protective mutualisms: a meta-analysis. PLoS ONE 5:e14308.

Weyl, E. G., M. E. Frederickson, D. W. Yu, and N. E. Pierce. 2010. Economic contract theory tests models of mutualism. Proceedings of the National Academy of Sciences of the USA 107:15712-15716.

Wheeler, W. M. 1942. Studies of Neotropical ant-plants and their ants. Bulletin of the Museum of Comparative Zoology 90:1-262.

Willmer, P. G., and G. N. Stone. 1997. How aggressive ant-guards assist seed-set in Acacia flowers. Nature 388:165-167.

Yu, D. W. 2001. Parasites of mutualism. Biological Journal of the Linnean Society 72:529-546.

Yu, D. W., and N. E. Pierce. 1998. A castration parasite of an antplant mutualism. Proceedings of the Royal Society B: Biological Sciences 265:375-382.

Associate Editor: Elizabeth Elle Editor: Ruth G. Shaw 